\title{
The Theory and Practice of Teaching and Guiding Legal Research Skills*
}

\author{
Ian Curry-Sumner \& Marieke van der Schaaf
}

\begin{abstract}
The aim of this article is to present a case study of the development process and its underlying theoretical fundaments of a research skills line in the law degree programme. Broader educational purposes of the article are to give managers and lecturers of law schools suggestions for implementing research skills in their curriculum. Accordingly, the article is aimed at stimulating students' research skills. This article will discuss the background to the decisions that were made in the Utrecht School of Law, then discuss the ultimate end result, namely the implementation of a new research skills line and the publication of a standard research skills instruction. Furthermore, each section will commence with a brief outline of the theoretical framework, followed by an explanation of how this theory has been practically implemented in the Bachelor of Law in Utrecht.
\end{abstract}

\section{Background}

\subsection{Introduction}

A student graduating with a law degree from a university in The Netherlands must be able to conduct independent academic research. Conducting research requires research skills, coupled with advanced knowledge about the law. It is widely agreed that a specific learning environment aimed at teaching and guiding law students' research may enhance the development of students' research skills. This starting point is certainly one that the Utrecht School of Law ascribes to. However, if one asks the question how a law school should approach the issue, responses vary enormously. In 2008, the Utrecht School of Law appointed a working group to examine how the quality of the research skills amongst bachelor students could be improved. This article presents those findings, as well as the solutions adopted by the Utrecht School of Law. These solutions are furthermore placed within the framework of fundamental educational science research. This combination of theoretical context and practical application forms the golden thread throughout this article.

* Ian Curry-Sumner is Associate Professor (Senior University Lecturer), UCERF, Molengraaff Institute for Private Law, Utrecht University, as well as coordinator of the Research Skills Project in Utrecht. Recently he published Research Skills: Instruction for Lawyers together with F. Kristen, T. van der Linden-Smith and H. Tigchelaar. Marieke van der Schaaf is Assistant Professor (University Lecturer), Department of Educational Sciences, Utrecht University. 


\subsection{Educational context}

Research skills are comprised of many different facets, such as formulating research questions, identifying possible sources and reporting the research. These facets come together in different places in the legal curriculum. However, an overarching line throughout the curriculum is sometimes difficult to identify. ${ }^{1}$ That was certainly the case in Utrecht anno 2008. The Utrecht School of Law decided in 2008 to attack this issue head-on. A project group was established with the aim of improving the quality of the bachelor thesis. In order to achieve this aim, a steering group was formed under the leadership of one of the current authors of this article (namely Ian Curry-Sumner), with the other members emanating from different institutes within the School of Law. ${ }^{2}$ The steering group was in turn assisted by the project group which comprised lecturers from all the various institutes of the School of Law, namely private law (Ian Curry-Sumner), international and European law (Arie Trouwborst), constitutional and administrative law (Aletta Blomberg), legal theory (Tina van der Linden-Smith and Jet Tigchelaar) and criminal law (François Kristen). Initial discussions within the context of the project group focused on formulating the scope of the task at hand. In order to do so, attention first had to be paid to identifying the skills regarded to be essential to produce a written academic research report. This early period of discussion was ultimately essential in ensuring that the project remained focused and delineated.

At the same time and early in the discussions, the steering group determined that more information was required with regard to the extent and the exact nature of bachelor students' underperformance in doing research. Therefore, all lecturers involved in teaching and assessment of the bachelor dissertation were requested to identify the specific research skills (using the list of research skills previously identified by the project group as necessary in writing an academic piece) in which students currently consistently underperform. After interviews with twenty-one bachelor dissertation lecturers, the overwhelming response to the question (in varying degrees) was that students consistently encounter difficulties with the formulation of the research question, ${ }^{3}$ as well as the proper reporting of their research (i.e. issues relating to correct language use, structure and citation). When questioned further, many lecturers explained that the students had not acquired certain basic skills necessary to write an academic legal analysis, ${ }^{4}$ noting that the ultimate quality of the written piece was lower than expected. In general

1 Skills courses have, for example, been introduced in Maastricht and Tilburg. In Maastricht, skills courses are offered in the first year and awarded a total of 8 ECTS across two courses (Bachelor Rechtsgeleerdheid and Bachelor European Law School Regular Track) and 9 ECTS across three courses (Bachelor European Law School English Language Track). Although the Tilburg skills track spans all three years of the bachelor, the focus is firmly on information skills (i.e. search skills), as well as writing and presentation skills. Leiden also offers compulsory writing skills courses in the first year.

2 The other members of the steering group were: François Kristen, Tina van der Linden-Smith and Jet Tigchelaar.

3 Approximately $95 \%$ of those questioned.

4 Approximately $75 \%$ of those questioned. 
it turned out that for many law lecturers the schism between expectation and reality with respect to the quality of the bachelor dissertation lead to frustration.

In analysing this phenomenon, two different problems need to be distinguished. Firstly, students find it difficult to apply skills learnt in one subject in a different context. In educational science terms this issue is known as 'knowledge transfer'. Although it is evidenced that most research skills are strongly bound to specific content domains (i.e. subject specific skills such as the search for international case law from a United Nations tribunal or the search for a specific preparatory document to a national piece of legislation), ${ }^{5}$ it is possible to stimulate the transfer of research skills from one domain to another (e.g. from property law to criminal law). Horizontal transfer from one content domain to another can be achieved through different means, for example (a) by practicing research skills in different contexts within the same sub-domain or (b) by promoting reflection of the skills taught (e.g. by stimulating discussion of the skills and the manner in which these skills have been developed). ${ }^{6}$ Anno 2008, students in Utrecht were primarily confronted with research skills training in two subjects: the compulsory core subjects offered in Public International Law (Kernvak Internationaal Recht) and Constitutional and Administrative Law (Kernvak Staats- en Bestuursrecht) during the first year and a half of study. The limited number of contexts in which students practiced research skills may have contributed to a diminished possibility for horizontal transfer.

Secondly, the question arose whether the traditional methods used to teach students these skills were suitable. This issue is, therefore, related to the didactical concept behind teaching research skills in a legal setting. In the traditional curriculum, instruction and research assignments were structured and followed along a pre-determined sequence resulting in students concentrating on executing a standard procedure of doing research, without serious reflection on the scientific reasoning as a core characteristic of academic research (Chinn \& Malhotra 2002, p. 175-218). As a result, students may often have a non-academic view of research.

\subsection{Aim and structure of the article}

With these two problems in mind, the Utrecht School of Law embarked on an ambitious project to identify the problems surrounding the level of bachelor research skills and subsequently attempted to solve the problem or at least improve the situation. The aim of this article is to present a case study of the development process and its underlying theoretical fundaments of a research skills line in the law degree programme. Broader educational purposes of the article are to give managers and lecturers of law schools suggestions for implementing research skills in their curriculum. Accordingly, the article is aimed at stimulating students' research skills. This article will discuss the background to the decisions that were made in the Utrecht School of Law, then discuss the ultimate end 
result, namely the implementation of a new research skills line and the publication of a standard research skills instruction. Furthermore, each section will commence with a brief outline of the theoretical framework, followed by an explanation of how this theory has been practically implemented in the Bachelor of Law in Utrecht.

This article is divided into eight sections. After this initial introduction (section 1), attention will be paid to the concept and content of research skills: what are research skills and what makes these skills distinct from others? (section 2). The main sections of this article will focus on how such skills can best be developed and stimulated in a legal educational setting (section 3). Four examples will be provided of how this can best be achieved by means of elucidation of goals and objectives (section 4), the instruction and guidance offered (section 5), the tasks or assignments for the students (section 6), as well as the assessment of the submitted work (section 7). The article will conclude with a summary of the results achieved in Utrecht, along with an indication of the future progress in this field (section 8).

\section{Research skills}

\subsection{Theoretical framework}

Developing students' research skills is a critical component of contemporary higher education. In many countries and disciplines, students carry out research projects that involve a longer time-span (e.g. a few weeks or months). In such open inquiries, students have freedom to explore questions and problems of their own interest. For example, in many comparative law courses at the Utrecht School of Law students are required to draft a comparative research paper in a small group on a topic of their choosing. They often have the entire teaching period (i.e. eight weeks) to draft their research question and write the final research report (Chinn \& Malhotra 2002, p. 175-218). Accordingly, students need to plan and carry out their own investigation and reflect on the research process (Zion et al. 2005, p. 959-983). Furthermore, students' reflection on their process and overall quality of the research is needed to enhance their deeper understanding of research (Gott \& Duggan 1995; White \& Frederiksen 1998, p. 3-118). For example, students should evaluate their own research process and make adjustments to ensure that the methods employed to collect their materials are suitable to attain their research objectives and thus ultimately answer their proposed research question. This requires that students are self-regulated learners able to control their own learning and to self-monitor and self-evaluate their research process. In Utrecht, this process culminates in the final bachelor year with the submission of a bachelor dissertation (Bachelor Afstudeerwerk), in which all the skills learnt during the bachelor are brought together in a final research project. ${ }^{7}$

7 In Utrecht, this final dissertation project is also offered in the form of a course, meaning that students have eight weeks to complete the research cycle. 
The word 'research' is, however, used in different contexts. Sometimes it represents content, i.e. a body of knowledge relating to the meaning of research that students need to master (in this sense as a noun), whereas in other contexts it is used to refer to a process in which student participate when they carry out research (in this sense as a verb) (Hodson 1992, p. 65-77; Kirschner 1992, p. 273-299; Lunetta et al. 2007, p. 393-441; National Research Council 2000). This article focuses on both; how students come to terms with the underlying knowledge base, as well as the meaning of research by means on on-the-job practice i.e. by being involved in research projects. A research process is iterative in nature and comprises a number of individual features: (a) posing academically oriented questions; (b) gathering evidence in responding to questions; (c) formulating explanations from evidence; (d) connecting explanations to academic knowledge; and (e) communicating and justifying the explanations (National Research Council 2000). Carrying out research is cognitively complex and demanding (Blank 2000, p. 486-506; Kuhn et al. 2000, p. 495-523; Zion et al. 2004, p. 728-753) since conceptual, procedural and contextual knowledge are needed for decision making, as well as certain skills and attitudes towards careful execution, proper processing of data, consistent reasoning, and critical evaluations (Lunetta et al. 2007, p. 393-441; Stokking et al. 2004, p. 93-116).

\subsection{Practical application in the legal context}

Much has been written in the educational science world about the difference between generic skills and domain specific skills. Domain specific skills with respect to the law degree refer inter alia to the ability to apply legislation, read and analyse case law, the ability to solve a case, advise a client, draft contracts or argue in court. These skills are domain specific in the sense that they are not required of a biology or medical student. Although there is currently no general agreement upon the division of skills between the general and the domain specific, it would appear that in the legal textbooks, general consensus is present with regard to the core domain specific skills. ${ }^{8}$ This skill set would also appear to largely correlate with the legal skills set identified during the mid-term evaluation of the legal bachelor in Utrecht in 2006 (Faculteit Rechtsgeleerdheid 2006, p. 27).

General skill sets refer to those skills that are not specific to a particular discipline. For example, all students, regardless of their discipline, should be able by graduation to independently formulate a research question. Although obviously domain specific issues will arise with respect to the precise formulation of this question, the skill sets required to formulate a research question are similar enough between the disciplines to talk of an overarching general skill set.

In identifying a general set of academic skills, it must be noted that this list bears great resemblance to a general set of research skills. It is in fact the set of research skills that form the core general academic skills set. With this in mind, the focus

8 For example, in Loonstra \& Mok 2008 chapters are devoted to using a statute book, reading and analysing legislation, finding, using and analysing case law, using legal literature, using parliamentary proceedings, answering a fact pattern and case management. 
of the first skills trajectory in the Utrecht School of Law is on research skills. This obviously does not exclude the creation of other skills lines within the legal bachelor programme, for example a legal skills line or a presentation skills line. After three months of discussion and debate in the aforementioned project group, six phases in a research process were identified. Although aware of the fact that a research process is not linear, the creation of six phases readily assists in the teaching of the various skills, as long as attention is paid to the constant reinforcement of the idea that the skills are interlinked and one must constantly refer back to one's original research question and as required amend, change, improve or remove.

The following list of research skills was identified and divided across six phases within the research process.

\section{Phase 1: Preparing the research}

Phase 1a: Acquaintance with the subject

1.1 Preparing the choice of a subject

1.2 Understanding the difference between having a subject and a research question

1.3 Ability to use methods that enable you to move from subject to research question

1.4 Being aware of the different selective properties of the research question

1.5 Understanding the different types of research questions and having the ability to select the research question that is most suitable for your own study

1.6 Ability to distinguish between the formulation of the research question and the research objective

1.7 Determining whether the research question is achievable considering the restrictions

1.8 Delineating the subject

1.9 Operationalisation of the research question

1.10 Having/activating the knowledge required to conduct the study

Phase 1b: Formulation of the sub-questions

1.11 (Functional) formulation of the sub-questions

1.12 Ability to structure sub-questions logically

1.13 Breaking down different elements of the questions

1.14 Outlining the research plan/designing the research plan

1.15 Ability to use the research question to create chapters with subsections

Phase 1c: Justification of the study/sources

1.16 Ability to indicate the social relevance of the research

1.17 Ability to indicate the academic relevance of the research

1.18 Ability to justify the selected method 


\section{Phase 2: Collecting the material}

2.1 Establishing different kinds of sources

2.2 Drawing up a search plan

2.3 Establishing search terms and a search strategy

2.4 If necessary, making a list with interview questions

2.5 Finding sources at different levels

2.6 Recording and compiling registers of sources

\section{Phase 3: Assessing the material}

3.1 Identifying possible sources

3.2 Insight in the academic character, quality and reliability of a text

3.3 Understanding the difference between an academic legal text and other research

3.4 Ability to assess general legal sources

3.5 Ability to assess electronic legal sources

\section{Phase 4: Structuring the report}

4.1 Understanding the function of an introduction

4.2 Ability to draft an introduction

4.3 Understanding the function of the main body of the text

4.4 Ability to draft the main body of the text

4.5 Understanding the function of a conclusion

4.6 Ability to draft a conclusion

\section{Phase 5: Structuring the reasoning}

5.1 Ability to link with the research question

5.2 Identifying the arguments for and against different points of view

5.3 Analysing and balancing the arguments

5.4 Structuring the arguments according to meaning and priority

\section{Phase 6: Reporting the research}

Phase 6a: Presenting the research

6.1 Understanding the influence of the audience on the form of the research report

Phase 6b: Oral presentation

6.2 Can use audio-visual aids (e.g. presentation software)

6.3 Useful pointers: eye contact, use of voice, gestures, attitude etc.

6.4 Practising the presentation

Phase 6c: Written presentation

6.5 Form: Understand the different forms of research report

6.6 Content: Informative, correct arguments, consistent etc.

6.7 Style: Correct and accurate use of language, well-written 

6.8 Lay-out: Headings, font etc.
6.9 Acknowledgement of sources: Correct, accurate, no plagiarism etc.
6.10 Reread and revise: Re-read your own text

\section{Phase 6d: Reflection \\ 6.11 Reflecting on the research process and suggesting improvements for the next time}

\section{Development and stimulation of research skills}

Generally, a curriculum that develops students' research skills is based on an explicit model of the way in which such skills develop. Utilising this approach with legal research is not wholly satisfactory since an adequate theoretical model for describing and explaining the development of research skills is not yet available. Well-known models for skills development in educational science literature involve psycho-motoric skills or simple cognitive skills (Anderson 1982, p. 369-406; Fitts \& Posner 1982) and are not well suited to research skills in the other contexts, e.g. the legal context (Stokking \& Voeten 2000, p. 101-118; Veenhoven 2004). Though it is often assumed that development takes place in sequential phases, the development of research skills can be an irregular process within which sudden or somewhat unexpected improvements can occur. Consequently, there is no conclusive model of the development of research skills to aid in structuring the creation of a learning line in a curriculum (Stokking et al. 2004, p. 93-116). As knowledge is one of the main contributing factors in stimulating further learning processes (Bransford et al. 2000), many argue that the most important condition both for doing, as well as for learning to do research is having relevant prior knowledge. At the same time, having prior knowledge can be a problem when this knowledge contains misconceptions or general, everyday notions that do not correspond with academic concepts (e.g. the concept of offer in contract law). Although students can have misconceptions concerning academic content, they also misunderstand the nature of academic knowledge and the way it is developed and tested (Blank 2000, p. 486-506; Bruner 1963; Khishfe \& Abd-El-Khalick 2002, p. 551-578; Osborne 1996, p. 53-82). It is therefore often argued that alongside the actual explorative practical process of conducting research, students also must receive explicit and continuous instruction and feedback in order to ensure the constant interaction between thought, action, and discussion (Gott \& Duggan 1995; Lederman 1999, p. 916-929; Zion et al. 2005, p. 959-983). Instruction and feedback in such a way ensures that the distance between students' actual developmental level in a certain (research) task and the level that will be accomplished with guidance can be bridged (Vygotsky 1978). Such instruction and feedback can have many forms, depending on the needs of students (e.g. directed instruction, questioning, providing hints etc.). For instance, it has been shown that when students' research related cognitive activities (which can be based on misconceptions), such as the steps they undertake to solve a given problem, are discussed with their tutors deeper learning can be 
achieved (Aleven \& Koedinger 2002). In an ideal situation the stimulation of students' research skills is based on a learning line in which learning objectives correspond to the level of the students. Since the development of research skills amongst individual students can differ, it is also important to have a learning line that is flexible enough to provide students with an anchor in this learning process. At the same time, this learning line should also aim to provide an anchor to lecturers in creating coherence in their own teaching.

In creating a learning environment that is conducive to the learning of research skills, attention must be paid to a number of different aspects. The main components of the learning environments lecturers can create for their students are the goals and objectives (section 4), the instruction and guidance (section 5), the tasks or assignments for the students (section 6), and the assessment (section 7). The subsequent sections will therefore focus not only on the practical implementation of the research skills line and instruction in Utrecht, but will place these developments in the theoretical framework of the educational sciences.

\section{Goals and objectives}

\subsection{Theoretical framework}

While teaching students how to do research, lecturers can strive for different goals (Gott \& Duggan 1995; Hodson 1992, p. 65-77; Kirschner 1992, p. 273-299; Meester \& Kirschner 1995, p. 127-140; Thair \& Treagust 1997, p. 581-597), for example (a) to motivate students, (b) to allow students to experience independent or cooperative assignments, (c) to illustrate phenomena and concepts, (d) to gain hands-on experience, (e) to contribute to the development of their subject knowledge, (f) to train them in practical skills (e.g. correct citation of legal sources), (g) to experience authentic tasks as a researcher, (h) to systematically execute certain activities, (i) to let them think as a researcher, and ( $j$ ) to let them experience the 'ethos' of research and academia.

In the everyday practice of teaching and guiding students' research skills, lectures generally focus on: (i) developing students' scientific knowledge by means of doing research; (ii) motivating and activating students' learning by (collaboratively) working on open research assignments; as well as (iii) developing students' research skills (Rijborz 2003). Teaching aims provide specific detailed information with regard to the behaviour students should demonstrate at the end of the course, as well as the requirements according to which these skills need to be acquired and the criteria for the assessment of these skills. These teaching aims form an important starting point for the creation of a learning line. In order to accurately formulate these teaching goals, two different sets of skills need to be distinguished, namely the underlying basic skills as well as the overarching complex skills. These two sets of skills can be linked to each other by means of a hierarchy, with the overarching complex skills at the top of the hierarchy and the basic underlying skills forming the necessary foundation to be able to successfully complete the overarching complex skills (Van Merriënboer \& Kirschner 2007). 


\subsection{Practical application in the legal context}

The application of this theoretical context in a legal setting has proven to be somewhat challenging. Although certain aspects, such as the training of practical skills, have traditionally formed an integral role in the legal bachelor, other aspects have not. ${ }^{9}$ In the end, the goals to be achieved have been formulated through the precise formulation of the research skills in the instruction book (as mentioned in the section 1.2 and 1.3). Each substantive law course in Utrecht dealing with the instruction of legal research skills is therefore expected to use the research skills instruction book as the point of reference in determining the teaching goals with regard to research skills. This process has thus ensured continuity in the teaching goals throughout the bachelor programme, as well as visibility of the research skills line throughout the bachelor curriculum.

Traditional legal skills training has also departed from the assumption that students should commence the research skills training from the point of a researcher, namely in formulating a research question; this is after all the start of all research. However, upon reflection it was decided not to depart from this position. Instead, attention was paid to the hierarchical nature of the research skills themselves. What is necessary in all research and what is necessary dependent upon the sort of research that one is conducting? More attention will be paid to this particular issue later in this article in section 5.2.2.

\section{Instruction and guidance}

\subsection{Theoretical framework}

Lecturers having to decide how to teach research have to make choices on several dimensions. Firstly, they have to decide the context in which to teach the students. Nowadays it is common to assume that broad, complex skills such as research skills should preferably be taught in authentic contexts. Connected to this is a second choice, namely whether to teach the separate sub-skills individually followed by integration, or focus immediately on meaningful wholes. There is evidence that the latter would be preferable because it better complements the manner in which complex skills develop (Hodson 1992, p. 65-77). Thirdly, lecturers can choose to install a learning sequence (conform a learning line) from easy to difficult, either with regard to subject content (conceptual) and/or with regard to research method (procedural). Fourthly, lecturers have to determine how much to structure the learning process through assignments and guidance (on a learning line), and how much to leave to the students themselves. Obviously lecturers might vary the amount of structure, fitting in with the complexity of the research and with the students' experience. In general, bachelor students have little experience in doing research and thinking scientifically. A very structured learning environment, in which the students almost have no space for making choices, is counter-productive (Roth \& Roychoudhury 1993, p. 127-152). The

9 For general material on legal research skills and legal research skills training see: Brayne \& Breakey 1996; Clinch 1991 and 1994; Midgal \& Cartwright 1991. 
same is also true for a very open learning environment, in which the students are thrown in at the deep end and left to their own resources (Fradd \& Lee 1999, p. 14-20). It has been empirically proven that the approach of pure discovery learning (i.e. prohibiting any intervention from lecturers) neither increases learning transfer nor subject-matter learning and the acquisition of basic scientific skills (Anderson et al. 1997, p. 18-21; Mayer 1987). This may demand too much 'cognitive load' of novice researchers, meaning that the capacity of the working memory is exceeded (Van Merriënboer \& Kirschner 2007). When working on complex assignments, students learn best by 'guided reinvention' (i.e. not too open, not too structured), because both extremes lead to superficial learning (Kanselaar et al. 1999). Accordingly, lecturers should provide balance in their instruction and guidance with respect to the degree of structuring and guiding students' learning process. A proper way of preventing students suffering from too much cognitive load is by means of sequencing learning tasks from simple to complex. ${ }^{10}$

Furthermore, according to the instructional design literature, to facilitate learning the different components of the learning environment must be consistent with each other. There are indications that better results are achieved in educational settings where the curriculum and the assessment methods are aligned (Cohen 1987, p. 16-20). Therefore, an appropriate learning environment for research is not just a matter of adequate separate components. All components should address the same agenda and support each other: the objectives are clearly stated in terms of the research skills needed, the teaching methods support students conducting the research, and the assessment addresses those same research skills. With the term 'constructive alignment', Biggs (1996, p. 347-364) proposes a marriage between constructivism as a framework for instructional design and the principle of alignment. The principle of constructive alignment means that lecturers are expected to be clear in the goals they pursue; to choose for studentoriented instruction and guidance; to work with authentic assignments fitting with the students' level; to be authentic in their assessments; and to make these components fit together.

\subsection{Practical application in the legal context}

The Utrecht approach consists of two separate, yet interrelated elements: the introduction of a research skills line coupled with the publication of a standard research skills instruction. Each of these elements will be discussed in this section, relating the various elements to the theoretical framework outlined above.

\subsubsection{Standard research skills instruction}

The ultimate product of the discussions of the steering group in Utrecht was the creation of a standard research skills instruction. The book consists of four main chapters: the list of research skills (chapter 1), the instruction of these skills (chapter 2), the assessment of the skills (chapter 3), and examples of standard feedback forms (chapter 4). These four chapters should be read in combination 
with each other and form an integrated whole. By means of colour-coding and cross-referencing, the skill-sets are fully integrated with each other. In this way, it is hoped that the linear structure of the book will not hinder the somewhat cyclical nature of the research experience.

In this context, the research skills instruction forms the basic guide for all legal bachelor students in Utrecht. The book is not intended to be read from cover to cover in the first course. Instead, students are introduced to each set of skills progressively throughout the curriculum. Accordingly, the research skills instruction serves as the necessary means of support in the creation of the research skills line, as will be discussed in section 5.2.2.

\subsubsection{Research skills line}

This section will deal with three different choices that have been made in Utrecht with regard to the introduction of a research skills line, namely the choice for a research skills line, the positioning of the various skills in the degree programme and the positioning of the associated instruction of the skills.

Firstly, the choice was made for a research skills line that was integrated into the subject-related courses, instead of separate skills course. As was explained in the introduction Utrecht has opted for a research skills line that spans the entire three years of the bachelor programme. Instead of creating a separate research skills or general skills programme, the skills line has been fully integrated into the existing subjects. In this manner, an attempt has been made to ensure that the problems associated with knowledge transfer can be solved, or at least alleviated. Students are now made aware of the fact that they are learning non-subject specific skills, alongside the subject-related content. Furthermore, the research skills line provides a general overarching framework within which students are confronted with different skills at different moments in the bachelor. Nonetheless, although this line requires a standard sequence in which the skills are to be trained, students are provided with flexibility when it comes to learning the individual skills. In this way, a compromise has been reached between the need for structured learning on the one hand, and the need for an open learning environment on the other.

Once the decision was reached to implement a research skills line throughout the entire bachelor programme, the next question of when each skill should be addressed in the subject-related courses arose. As was stated in section 2.1, it is essential that lecturers and organizations appreciate that certain skills must be acquired prior to the development of other skills. Previous experience in Utrecht has led to the conclusion that requiring students to formulate research questions in the first year can lead to problems. These considerations coupled with the desire to avoid superficial learning and promote guided reinvention, promoted Utrecht to opt for a 'backwards approach' to the research skills line. To fully understand this approach, one first needs to appreciate the structure of the Utrecht law degree. The bachelor is divided into three main sections: 
1. Foundational section: During the first six months, students are introduced to the basic principles of law (Grondslagen van het Recht) and provided with a general introduction to various subjects (Inleiding Privaatrecht, Strafrecht en Staats- en Bestuursrecht).

2. Core section: In the subsequent two semesters ${ }^{11}$ students study the eight core subjects of law: property law, the law of obligations (contract and tort), substantive criminal law, criminal procedural law, constitutional law, administrative law, international law and European law. In Utrecht these subjects are called kernvakken.

3. Choice section: Contrary to the first half of the degree programme, the second half is characterised by choice. Nevertheless, despite the apparent superficial freedom, students do have to choose within a range of specific groupings if they wish to receive a declaration of 'civiel effect' that will entitle them to enter into the legal professions at a later date, they have to choose certain subjects. For example, procedural law, company and commercial law, a comparative law subject, a context-related subject (legal sociology, legal philosophy and so on), as well as a course in general legal theory (algemene rechtsleer).

These three sections also form the basis for instruction in the research skills. Alongside the content-related subjects in the 'foundational section', 'foundational research skills' are introduced, namely structure, legal reasoning and reporting. For example, specific attention is paid to the necessary components of an introduction, as well as the need to cite legal sources correctly and consistently (in terms of the research skills instruction this is equivalent to phases 4, 5 and 6). In the second 'core section', in which students focus on the 'core' content-related subjects of the law, the research skills line follows suit and shifts attention to the 'core research skills', namely the ability to collect and assess ones sources (in terms of the research skills instruction this is equivalent to phases 2 and 3). In the seminar groups, students are no longer provided with extracts from existing case law. Instead students have to find the relevant case law and statutes themselves, and subsequently answer the content-related questions concerning these cases. In the third and final 'choice section', the degree is typified by the ability for students to choose subjects in which they are interested (within certain parameters). Once again the research skills line follows suit, introducing students to the most complicated research skills, namely those focusing on the choice of a subject and the formulation of a research question (in terms of the research skills instruction this is equivalent to phase 1 ). Students are not only introduced to the 'choice research skills', but also to the need to justify choices that are made.

Thirdly, special attention was paid to the concept of 'constructive alignment' in implementing the instruction session on informational research skills (i.e. search strategies). Unlike in previous years, Utrecht has now opted not to have the law library practical in the first week of the first year. As has already been stated, law 
students are now first trained in foundational research skills, namely the structure, legal reasoning and reporting of a research report. During the first six months students are, therefore, not required to find case law and legal statutes. ${ }^{12}$ Providing a library practical in this semester therefore leads to a 'non-aligned' skills programme. Instead, Utrecht now offers all first years students a law library practical in April of the first year (i.e. in the second semester). This two-hour practical is divided into two separate hours. In the first hour students receive instruction from an older student-mentor. The student-mentor explains the basic framework of search strategy and the database available. The student-mentor ensures an approachable and accessible environment in which the skills are introduced and students are able to ask questions in a non-daunting setting. At the end of this session students are provided with a number of assignments that they are to do at home. The following week, students return to the law library and receive a further hour of instruction from law librarians with specialised expertise in information skills.

Perhaps the most innovative part of this new structure is that the two subjectrelated courses that students follow at the time of the practical (property law and constitutional law) have fully integrated these search skills into their regular teaching. Each week students are given a content-related question in which they first are required to 'find' the relevant case or statute. The complexity and difficulty of the search strategy gradually increases throughout the course, ensuring that by completion of the courses a student should be able to find cases and statutes in a variety of different subjects at a relatively high level of complexity. This system ensures that students are provided with instruction, as well as the opportunity to practice those skills immediately in an authentic educational and practical setting. This process is repeated in the second half of the core subjects when students are asked to search for legal literature. Again the assignments are provided within the seminar groups for the law of obligations and administrative law.

\section{Assignments}

\subsection{Theoretical framework}

In a learning environment featured by independent learning, as expected in Dutch upper secondary education, a substantial part of students' learning takes place as they work on assignments. The main features of assignments which can improve the work and the learning of students are well known: the problem is recognizable for them and is seen as relevant; the problem is challenging (not too easy nor too difficult); the work should result in a final product; students are allowed to cooperate; there is a variety of tasks to be done; and there is room for students to make choices of their own (Blumenfeld et al. 1991, p. 369-398). Dutch

12 Nevertheless, it must be noted that students can of course search for case law and statutes of their own volition to assist in the understanding of the concepts taught. Furthermore, it must be noted that this structure does not necessarily apply to the students participating in the Utrecht Law College programme. 
lecturers are used to varying the scope and difficulty of assignments and they often believe this to be easier than to varying the degree and nature of guidance (Vankan 2000).

Assignments can include various information and options: the choices that students still can or have to make; the sources and facilities to be used; the time planning; the way of cooperating; the guidance they can ask or will be given; the moments of assessment; and the assessment criteria. Especially the assessment criteria can be used to explain the learning aims and their importance and can make meaningful feedback possible. Clear goals and realistic feedback can be important motivators (Boekaerts 1991, p. 1-17; Crooks 1998, p. 438-481).

Additionally, the lecturer can provide students with opportunities to cooperate. Lecturers can let students cooperate for practical reasons, such as reduction in the number of assignments to be assessed. Cooperation can also be seen as a goal on its own because students in their future life will also have to work in teams. Additionally, cooperation can motivate the students and thereby further the learning process. Cooperation can also further students' learning directly if it triggers discussion and reflection on the research assignment in progress. Finally, lecturers have to make decisions about the coaching they will give the students, the frequency, amount and type of feedback, and the extent to which they stimulate reflection and self-assessment (Collins et al. 1989, p. 453-494). ${ }^{13}$

\subsection{Practical application in the legal context}

On the basis of the theoretical context in which assignments and research skills assessment need to be created, the Utrecht context is one characterized by interdisciplinary co-operation. Students embarking upon a bachelor of law in Utrecht will in the first semester be confronted with the research skills line in the course Principles of Law (Grondslagen van het Recht). In the context of this course students are provided with a set material and a legal research question. They are subsequently required to write a legal analysis in groups on the basis of this material. Accordingly, the focus in this subject is squarely founded on research skills that are required in the latter three phases of a research process, namely the structuring, reasoning and reporting of the research undertaken. In order to assist the students in developing these skills, they receive two forms of instruction, peertutor based instruction from older students (i.e. mentors) and one instruction session from university lecturers. By involving more advanced students, an accessible and approachable environment in which students feel comfortable airing their fears, queries and questions is created. The mentors are also able to explain the need to learn these skills from direct, first-hand experience. The mentors are often involved in final phases of their own bachelor or masters degree, thus enabling first-hand experience to be disseminated in an extremely informal and easily accessible manner. 
Moreover, sequencing learning tasks can be based on part-task or whole-task sequencing. Part-task sequencing starts with individual sections of the task at hand and works towards the whole task, whereas whole-task sequencing starts with a simplified version of the final task and works towards a more complicated version of the ultimate goal (Van Merriënboer \& Sweller 2005, p. 147-177). Although the whole-task sequencing in the context of the research process would at first glance appear to be the most obvious method, the Utrecht School of Law has instead opted for the part-task sequencing method. This is not, however, to say that whole-task sequencing does not form an essential component of the degree programme. Instead the first compulsory year and a half of the study is utilised not only in ensuring that students possess the necessary foundational knowledge to continue with their study, but all the necessary skills to do so. As a result, in the final year and a half of the study, any individual student will experience the whole-task sequence on multiple occasions (e.g. in the context of a comparative law subject or context based subject such as legal philosophy or legal sociology) prior to the ultimate test in the context of the bachelor dissertation.

\section{Skills assessment}

\subsection{Theoretical framework}

Assessing research skills by means of realistic research assignments is in tune with new assessment strategies known as performance assessment and authentic assessment. These strategies lead to a closer integration of teaching and assessment. Alongside a summative function, in which the achievements of students are assessed, the assessment also serves a formative function, whereby the assessment of the teaching process is also supported, for example in providing feedback in diagnosing problems or providing feedback (Stokking et al. 2004, p. 93-116). For instance, students can receive formative feedback throughout the process of working on their long-term research assignment and get a summative mark when they have completed the assignment. There is a body of firm evidence that formative assessment has the greatest impact on development and achievement (Hattie 2008), because it can enhance learning when it provides students with feedback about specific qualities of their work, and about how to improve (Black \& Wiliam 1998, p. 7-75; Kluger \& DeNisi 1996, p. 254-284). Especially students' involvement in their own assessment stimulates learning. For instance peer- and self-assessment increases students' responsibility for their learning and enhances understanding of criteria and standards for good performance.

In addition, lecturers have to make a number of specific decisions with regard to how often and what to assess, in addition to determining the assessment criteria, scoring, norms, and quality assurance. The assessment criteria will depend on the research steps or research skills emphasised by the lecturer, as well as course goals. Assessment criteria can assist lecturers to accurately assess students' research assignments. Assessment criteria can direct teachers' attention on what to assess and may contribute to a shared interpretation of students' work. Such 
criteria also can serve as an instruction to students that may guide them during their research process. Lecturers must also decide how to score: more analytically or more holistically. Analytical scoring involves the systematic scoring of research projects with respect to individual aspects of the research process, the final grade being based on the addition of the scores for the individual parts. Holistic scoring, on the other hand, refers to a general impression for the research project as a whole. Finally, the lecturers also need to ensure that they pre-determine their approach prior to assessment and communicate this to all involved.

\subsection{Practical application in the legal context}

From the start of this project, it was appreciated that the assessment criteria for grading of research reports and the provision of feedback were essential to the ultimate success of the implementation of the research skills line. Accordingly, two chapters in the research skills instruction focus on the assessment of research reports (chapter III) and the provision of feedback (chapter IV). The assessment criteria have been formulated as to focus on the overarching research skills instead of on the basic research skills themselves. ${ }^{14}$ General assessment criteria aimed at objectifying the assessment procedure have also been provided. These criteria enable students not only to determine the quality of their own research, but also provide a useful tool and structure when requiring students to undertake peer-review assessments.

Perhaps the most novel, and also challenging innovation is the introduction of a standard research project assessment form. The basic idea is simple: every time a student is required to submit a research-based assessment during their bachelor, the student will be provided feedback as regards the level and quality of their research skills. The assessment form is identical regardless of the subject, and therefore enables students to analyse their cross-content based research skills. Such a multi-purpose feedback form will also enable the bachelor dissertation lecturer to gain first-hand insight into the current level of any given student's research skills. This also means that a lecturer will be provided with the opportunity to furnish the student with tailored instruction and guidance as to how best improve those skills that require attention. Accordingly, it is hoped that the feedback forms serve both a summative, as well as formative function both in terms of the assessment of a given subject, as well as the improvement of the research skills of each student throughout the bachelor.

Uniformity often entails rigidity. To compensate for this and ensure that the research report feedback is tailored to the individual needs of the lecturer and course at hand, two aspects should be mentioned. Firstly, two blank spaces have been left available on the feedback form. These assessment criteria are left open to provide all lecturers with the ability to highlight specific assessment criteria. Secondly, two different assessment forms have been included, a standard form to be used in all cases, and an extensive assessment form should lecturers require 
more specific or extensive feedback. The assessment forms, with the combination of grading indications and room for comments provide a balanced approach to the systematic and holistic scoring approaches.

\section{Conclusion}

The development of complex research skills demands a learning environment in which students learn in a gradual, independent, active and cooperative manner and in a meaningful context. The teaching of such skills should be focused on mentoring and guiding the students' development with the content of different subjects being integrated into the process. The assessment of such skills forms an integral part of the learning environment. The intended result is that students learn to monitor the consistency and scope of the research as a whole.

In Utrecht these factors have ultimately been translated into the publication of a research skills instruction and the implementation of an accompanying research skills line. These innovative steps have, however, only recently been taken, and therefore empirical evidence is not available as to the effect that these changes have had on the final quality of the research reports submitted. Nonetheless, early indications are that the general level of the written reports has indeed increased, and that the students are much more aware of how and more importantly why they need to use legal databases in searching for legal materials.

\section{References}

\section{Aleven \& Koedinger 2002}

V. Aleven \& K.R. Koedinger, 'An Effective Metacognitive Strategy. Learning by Doing and Explaining with a Computer-based Cognitive Tutor', Cognitive Science 2002-2, p. 147-179.

Anderson 1982

J.R. Anderson, 'Acquisition of Cognitive Skill', Psychological Review 1982, p. 369-406.

Anderson et al. 1997

J.R. Anderson, L.M. Reder \& H.A. Simon, 'Situative versus Cognitive Perspectives.

Form versus Substance', Educational Researcher 1997-1, p. 18-21.

\section{Biggs 1996}

J. Biggs, 'Enhancing Teaching through Constructive Alignment', Higher Education 1996, p. 347-364.

\section{Black \& Wiliam 1998}

P. Black \& D. Wiliam, 'Assessment and Classroom Learning', Assessment in Education. Principles, Policy \& Practice 1998-1, p. 7-75.

\section{Blank 2000}

L.M. Blank, 'A Metacognitive Learning Cycle. A Better Warranty for Student Understanding?', Science Education 2000-4, p. 486-506.

\section{Blumenfeld et al. 1991}

P.C. Blumenfeld et al., 'Motivating Project-Based Learning. Sustaining the Doing, Supporting the Learning', Educational Psychologist 1991, p. 369-398. 


\section{Boekaerts 1991}

M. Boekaerts, 'Subjective Competence, Appraisals and Self-Assessment', Learning and Instruction 1991-1, p. 1-17.

\section{Bransford et al. 2000}

J.D. Bransford et al., How People Learn. Brain, Mind, Experience, and School, Washington DC: National Academy Press 2000.

\section{Brayne \& Breakey 1996}

H. Brayne \& P. Breakey, 'Legal Practice Course Research Skills. Teaching Competence or Raising Awareness?', Web Journal of Current Legal Issues 1996-3.

Brown et al. 1992

C.R. Brown et al., 'The Construct Validity and Context Dependency of Teacher Assessment of Practical Skills in Some Pre-University Level Science Examinations', Assessment in Education 1996-3, p. 377-391.

\section{Bruner 1963}

J.S. Bruner, The Process of Education, New York: Vintage Books 1963.

\section{Chinn \& Malhotra 2002}

C.A. Chinn \& B.A. Malhotra, 'Epistemologically Authentic Reasoning in Schools.

A Theoretical Framework for Evaluating Inquiry Tasks', Science Education 2002, p. 175-218.

\section{Clinch 1991}

P. Clinch, 'Legal Research Skills. Development of an Undergraduate Course', The Law Librarian 1991-2, p. 77-85.

\section{Clinch 1994}

P. Clinch, 'Practical Legal Research the Cardiff Way', The Law Teacher 1994-3, p. $270-280$.

\section{Cohen 1987}

S.A. Cohen, 'Instructional Alignment. Searching for a Magic Bullet', Educational Researcher 1987-8, p. 16-20.

Collins, Brown \& Newman 1989

A. Collins, J.S. Brown \& S.E. Newman, 'Cognitive Apprenticeship. Teaching the Crafts of Reading, Writing, and Mathematics', in: L.B. Resnick (ed.). Knowing, Learning, and Instruction. Essays in Honor of Robert Glaser, Hillsdale: Erlbaum 1989, p. 453-494.

\section{Crooks 1998}

T.J. Crooks, 'The Impact of Classroom Evaluation Practices on Students', Review of Educational Research 1998-4, p. 438-481.

\section{Curry-Sumner et al. 2010}

I. Curry-Sumner et al., Research Skills. Instruction for Lawyers / Onderzoeksvaardigheden. Instructie voor juristen, Nijmegen: Ars Aequi 2010.

\section{Faculteit Rechtsgeleerdheid 2006}

Faculteit Rechtsgeleerdheid, Een eind op weg. De juridische bacheloropleiding onder de loep gehouden. Evaluatierapport bachelor Rechtsgeleerdheid, Utrecht: Universiteit Utrecht 2006.

\section{Fradd \& Lee 1999}

S.H. Fradd \& O. Lee, 'Teachers' Roles in Promoting Science Inquiry with Students from Diverse Language Backgrounds', Educational Researcher 1999-6, p. 14-20.

\section{Fitts \& Posner 1982}

P.M. Fitts \& M.I. Posner, M.I, Human Performance, Belmont, CA: Brooks/Cole 1967.

\section{Gott \& Duggan 1995}

R. Gott \& S. Duggan, Investigative Work in the Science Curriculum, Buckingham: Open University Press 1995. 


\section{Hattie 2008}

J. Hattie, Visible Learning. A Synthesis of over 800 Meta-Analyses Relating to Achievement, London: Routledge 2008.

\section{Hodson 1992}

D. Hodson, 'Redefining and Reorienting Practical Work in School Science', School Science Review 1992-264, p. 65-77.

Kanselaar et al. 1999

G. Kanselaar et al., Grafieken leren met de computer, Utrecht: Brouwer-Uithof BV 1999.

\section{Khishfe \& Abd-El-Khalick 2002}

R. Khishfe \& F. Abd-El-Khalick, 'Influences of Explicit and Reflective versus Implicit Inquiry-Oriented Instruction on Sixth Graders' Views of Nature of Science', Journal of Research in Science Teaching 2002-7, p. 551-578.

\section{Kirschner 1992}

P.A. Kirschner, 'Epistemology, Practical Work and Academic Skills in Science Education', Science \& Education 1992, p. 273-299.

\section{Kluger \& DeNisi 1996}

A.N. Kluger \& A. DeNisi, 'The Effects of Feedback Interventions on Performance. A Historical Review, a Meta-Analysis, and a Preliminary Feedback Intervention Theory', Psychological Bulletin 1996, p. 254-284.

Kuhn et al. 2000

D. Kuhn et al., 'The Development of Cognitive Skills to Support Inquiry Learning', Cognition and Instruction 2000-4, p. 495-523.

\section{Lederman 1999}

N.G. Lederman, 'Teachers' Understanding of the Nature of Science and Classroom Practice. Factors that Facilitate or Impede the Relationship', Journal of Research in Science Teaching 1999-8, p. 916-929.

\section{Lock 1989}

R. Lock, 'Assessment of Practical Skills Part 1: The Relationships between Component Skills', Research in Science \& Technological Education 1989-2, p. 221-233.

\section{Loonstra \& Mok 2008}

C.J. Loonstra \& M.M. Mok, Juridische vaardigheden, Groningen: Wolters-Noordhoff 2008.

\section{Lunetta, Hofstein \& Clough 2007}

V.N. Lunetta, A. Hofstein \& M.P. Clough, 'Learning and Teaching in the School Science Laboratory. An analysis of Research, Theory, and Practice', in: S.K. Abell \& N.G. Lederman (eds.), Handbook of Research on Science Teaching, New Jersey: Lawrence Erlbaum Associates 2007, p. 393-441.

\section{Mayer 1987}

R.E. Mayer, Educational Psychology. A Cognitive Approach, Boston: Harper Collins Publishers 1987.

\section{Meester \& Kirschner 1995}

M.A.M. Meester \& P.A. Kirschner, 'Practical Work at the Open University of The Netherlands', Journal of Science Education and Technology 1995-2, p. 127-140.

\section{Van Merriënboer \& Kirschner 2007}

J.J.G. van Merriënboer \& P.A. Kirschner, Ten Steps to Complex Learning, Mahwah: Erlbaum 2007. 
Van Merriënboer \& Sweller 2005

J.J.G. van Merriënboer \& J. Sweller, 'Cognitive Load Theory and Complex Learning. Recent Developments and Future Directions', Educational Psychology Review 2005-1, p. 147-177.

Midgal \& Cartwright 1991

S. Midgal \& M. Cartwright, 'Student-Based Learning. A Polytechnic's Experience', The Law Teacher 1991-2, p. 120-131.

National Research Council 2000

National Research Council (NRC), Inquiry and the National Science Education Standards. A Guide for Teaching and Learning, Washington DC: National Academy Press 2000.

Osborne 1996

J.F. Osborne, 'Beyond Constructivism', Science Education 1996-1, p. 53-82.

Rijborz 2003

D. Rijborz, Leren onderzoeken. Leerlijnen bij praktische opdrachten in de tweede fase in het profiel 'Economie \& Maatschappij (doctoral thesis), Enschede: PrintPartners Ipskamp 2003.

Roth \& Roychoudhury 1993

W.M. Roth \& A. Roychoudhury, 'The Development of Science Process Skills in Authentic Contexts', Journal of Research in Science Teaching 1993-2, p. 127-152.

Stokking et al. 2004

K. Stokking et al., 'Teachers' Assessment of Students' Research Skills', British Educational Research Journal 2004-1, p. 93-116.

Stokking \& Voeten 2000

K. Stokking \& R. Voeten, 'Valid Classroom Assessment of Complex Skills', in: R. Simons, J.L. van der Linden \& T. Duffy (eds.), New Learning, Boston: Kluwer Academic Publishers 2000, p. 101-118.

\section{Thair \& Treagust 1997}

M. Thair \& D.F. Treagust, 'A Review of Teacher Development Reforms in Indonesian Secondary Science. The Effectiveness of Practical Work in Biology', Research in Science Education 1997-4, p. 581-597.

Vankan 2000

L. Vankan, Naar een model voor het maken van praktische opdrachten. Het POCO-model, Enschede/Nijmegen: SLO/ILS-KUN 2000.

\section{Veenhoven 2004}

J. Veenhoven, Begeleiden en beoordelen van leerlingonderzoek. Een interventiestudie naar het leren ontwerpen van onderzoek in de tweede fase bij aardrijkskunde (doctoral thesis), Utrecht: Utrecht University 2004.

Vygotsky 1978

L. Vygotsky, Mind in Society. The Development of Higher Psychological Processes, Cambridge MA: Harvard University Press 1978.

White \& Frederiksen 1998

B.Y. White \& J.R. Frederiksen, 'Inquiry, Modeling, and Metacognition. Making Science Accessible to All Students', Cognition and Instruction 1998-1, p. 3-118.

Zion et al. 2004

M. Zion et al., 'Dynamic, Open Inquiry in Biology Learning', Science Education 2004-5, p. 728-753.

Zion, Michalsky \& Mevarecht 2005

M. Zion, T. Michalsky \& Z.R. Mevarecht, 'The Effects of Metacognitive Instruction Embedded within an Asynchronous Learning Network on Scientific Inquiry Skills', International Journal of Science Education 2005-8, p. 959-983. 